\title{
Is Childhood Obesity Influenced by Dog Ownership? No Cross-Sectional or Longitudinal Evidence
}

\author{
Carri Westgarth $^{a} \quad$ Jon Heron $^{b} \quad$ Andrew R. Ness $^{c}$ Peter Bundred ${ }^{d}$ \\ Rosalind M. Gaskell ${ }^{a}$ Karen Coyne $^{a} \quad$ Alexander J. German ${ }^{\mathrm{e}}$ \\ Sandra McCune ${ }^{f}$ Susan Dawsong \\ ${ }^{a}$ Institute of Infection and Global Health, University of Liverpool, Liverpool, b ${ }^{\text {S }}$ chool of \\ Social and Community Medicine, 'School of Oral and Dental Sciences, University of Bristol, \\ Bristol, ${ }^{d}$ Institute of Psychology, Health and Society, ${ }^{e}$ Institute of Ageing and Chronic \\ Disease, University of Liverpool, Liverpool, ${ }^{f}$ WALTHAM ${ }^{\circledR}$ Centre for Pet Nutrition, Waltham- \\ on-the-Wolds, ${ }^{9}$ School of Veterinary Science, University of Liverpool, Liverpool, UK
}

\author{
Key Words \\ Childhood obesity · Dog $\cdot$ Human-animal interaction $\cdot$ Social determinants $\cdot$ Lifestyle \\ factors $\cdot$ Interdisciplinary $\cdot$ Epidemiology $\cdot$ BMI
}

\begin{abstract}
Objective: To examine whether dog ownership is associated with lower risk of childhood obesity. Methods: Cross-sectional study of 7,759 children at age 7 years in the Avon Longitudinal Study of Parents and Children (ALSPAC) in the UK. In addition, longitudinal analyses were conducted between age 7 and 9 years. BMI at age 7 and 9 years was calculated from clinic-measured weight and height and standardised in reference to 1990 UK data. Dog ownership data were collected by carer questionnaire at various time points. Results: After adjustment for confounding factors associated with dog ownership or obesity, there was no evidence of an association between obesity and dog ownership at 7 years $\mathrm{OR}=1.18,95 \%$ confidence inter$\mathrm{val}=0.88-1.59, \mathrm{p}=0.27$ ), or dog ownership history. There was also no evidence for an effect of dog ownership on BMI change between 7 and 9 years, nor acquisition of a dog on the change in weight status of obese children between 7 and 9 years. Conclusion: This study provides no evidence for a protective effect of dog ownership on the development of childhood obesity. Further investigation is required to determine the impact of dog ownership on physical activity in overweight and obese children.

Copyright (c) 2012 S. Karger GmbH, Freiburg
\end{abstract}


Westgarth et al.: Is Childhood Obesity Influenced by Dog Ownership? No CrossSectional or Longitudinal Evidence

\section{Introduction}

Childhood obesity is a major and increasing public health concern, with prevalence in the UK having risen rapidly in children as young as 3 years $[1,2]$. Obesity is caused by a positive mismatch between energy intake and energy expenditure [3], and risk factors include lower socio-economic status, parental obesity, maternal smoking and increasing birth weight [4].

Although owning pets may confer both physiological and psychological health benefits [5-7], studies have produced conflicting findings [8]. Pet ownership is hypothesised to provide emotional protection from the stresses and strains of life (the 'buffer' effect) [6] and may encourage a more active lifestyle [9]. Of particular recent interest to public health researchers is the relationship between dog ownership and physical activity in adults [9]. A number of studies (mainly from the USA and Australia) have suggested that higher physical activity can occur through dog walking [9-17]. This may have implications for obesity, a current major public health issue; one study suggested owners that walked their dog had lower weight status than dog owners who did not walk their dogs, or non-owners [16]. There is also some evidence of a link between obesity in dogs and their owners [18], with prevalence currently rising in both pets and humans.

There has been less research into dog ownership, obesity and physical activity during childhood. One recent UK study suggested that children's physical activity levels at age 9-10 years may be slightly higher if they own a dog [19]; however, whether the dog-owning children were also less likely to be obese was not reported. An Australian study suggested that dog ownership was associated with lower weight status in 5- to 6-year-old, but not 10- to 12 -year-old children, with a positive association with physical activity observed in girls only $[20,21]$. In contrast, another Australian study that examined adolescent children found no evidence of an association between dog ownership and either BMI or physical activity [22].

Dog ownership could be hypothesised to protect against development of obesity or even reduce BMI in already obese children. The study of the relationship between dog ownership and child health has interesting implications. If dog ownership were proven to facilitate physical activity and reduce the risk of obesity, responsible dog ownership could be promoted as a public health strategy. This raises ethical and welfare concerns on behalf of the animal and even the surrounding community, if it encourages dogs to be acquired without close regard to the full responsibilities and realities of dog ownership. A more appropriate prospective intervention strategy would be to encourage more walking with suitable dogs already owned by families. Interventions that encouraged everyone to be more physically active by walking their dog more frequently or for longer times would benefit children, parents and the dog [23]. As dogs already live in households with children and walking is free, it would be cheap to implement and accessible to many. Furthermore, given the disproportionately high prevalence of dog ownership in more deprived families [24, 25], the future reach of dogbased interventions into socio-economically deprived groups is potentially high.

This study used a large, well-characterised UK birth cohort (the Avon Longitudinal Study of Parents and Children - ALSPAC) to examine whether dog ownership during childhood is related to weight status at age 7 years, and weight change between 7 and 9 years. ALSPAC contains information on a wide range of potential confounding factors including socio-economic status. Factors associated with pet ownership in this cohort have been described elsewhere [25], as have early life risk factors for obesity at age 7 [4]. We hypothesised that i) at 7 years children who live with dogs would be less likely to be obese; ii) there would be a dose response effect with children who had owned a dog all their lives, as opposed to just recently, having lower weight status; and iii) acquisition of a dog would reduce BMI by age 9 in children categorised as obese at age 7 . 
Westgarth et al.: Is Childhood Obesity Influenced by Dog Ownership? No Cross-

Sectional or Longitudinal Evidence

\section{Material and Methods}

Data Collection

ALSPAC is a prospective study, described in detail elsewhere [26], that recruited 14,541 pregnant women resident in Avon, UK, with expected dates of delivery between April 1, 1991 and December 31, 1992. Of the initial 14,541 pregnancies, all but 69 had a known birth outcome and, of these, 195 were twin, 3 were triplet and 1 was a quadruplet pregnancy meaning that there were 14,676 foetuses in the initial ALSPAC sample; 14,062 were live births and 13,988 were alive at 1 year. The triplet and quadruplet children (13) were omitted for reasons of confidentiality and, therefore, the full dataset available for use in this paper was 14,663 foetuses. At baseline, the ALSPAC cohort was broadly representative of the UK population, although ethnic minority groups are slightly under-represented [26]. Ethical approval for the study was obtained from the ALSPAC Law and Ethics Committee and the Local Research Ethics Committees and the participants provided informed consent.

ALSPAC contains a number of measures of obesity and overweight [27]; in particular, BMI at age 7 years onwards can be calculated accurately for all children from measurements taken in focus clinics (rather than self-reports). BMI data collected at age 7 years in a focus clinic was available for 7,759 children. Height at age 7 and age 9 was measured to $0.1 \mathrm{~cm}$ using the Harpenden stadiometer (Holtain; Crymych, UK). Weight was measured to $0.1 \mathrm{~kg}$ using a Tanita TBF 205 body fat analyser and weighing scales. BMI was calculated as weight (in kg) divided by height squared (in metres) and converted to age-specific standard deviation scores (SDS) relative to 1990 UK data [28]. The dog ownership data have been described elsewhere [25]. Briefly, the carer of the child (usually the mother) was asked 'do you have any pets?' and 'how many of the following pets do you have?', during gestation, and at child age 8 months, 2, 3, 4, 7, 8 and 10 years. It was assumed that the child also lived with any dog reported by the carer, and in this paper we refer to children as 'owning' these dogs. Using two-step cluster analysis and including data up to age 7 years, three dog ownership type clusters were identified, and each child was assigned to a group subsequently termed i) never owned a dog; ii) sometimes owned a dog; and iii) always owned a dog [25]. The category 'sometimes owned a dog' mainly consisted of dogs that had been acquired relatively recently.

\section{Statistical Analyses}

BMI was interpreted in reference to 1990 UK data; an age-specific SDS for BMI equal or greater than 1.04 was used to determine a binary variable for 'overweight or obese', and SDS equal or greater than 1.64 to define 'obese' [28]. These represent the 85th and 95th percentiles respectively. Children with missing data for outcome or predictor variable of interest were excluded from analysis.

Binary outcomes for weight status at age 7 years were compared with binary outcomes for ownership of a dog at age 7 years using chi-squared tests and logistic regression. They were also compared with the variables describing history of dog ownership up to age 7 years.

Analyses were then adjusted in two models: model 1 adjusted for factors identified previously in this cohort as associated with ownership of dogs [25] (concurrent ownership of bird, fish, 'other' pet, number of people in household, presence of an older sibling, maternal social class, paternal social class, paternal education, maternal age at delivery, house type, whether mother owned pets as a child); model 2 adjusted for factors associated with risk of obesity [4] (maternal education, maternal social class, maternal smoking during pregnancy, parental obesity, gender of child, birth weight, TV watching at 38 months, sleep duration at 30 months). This model by Reilly et al. [4] used maternal education as a proxy for 'maternal social class'. Both maternal social class and education are available in the dataset and have been shown to be associated with pet ownership [25]. In order to adjust for confounding by social position, we chose to use both maternal social class and maternal education in both models.

Stratification was also used to produce sub-samples of those with or without a dog at age 7 years or obese or not obese at age 7 years, and to examine changes in BMI and obesity between age 7 and 9 years. Chi-squared and Fisher's exact tests were used to compare groups of ordinal variables, and t-tests or paired t-tests were used as appropriate for continuous variables.

\section{Results}

The characteristics of the sample at age 7 years focus clinic $(n=7,759)$ are described in table 1 . The percentage of children categorised as overweight or obese was $17.6 \%$, and obese was $8.4 \%$. 
Table 1. Characteristics (number and percentage) of the study children at 7 years (85 months) ${ }^{\mathrm{a}}$

\begin{tabular}{|c|c|c|c|}
\hline Variable $\left({ }^{*}=\right.$ specific to 85 months) & Level & Number & Percentage \\
\hline Overweight or obese & $\begin{array}{l}\text { yes } \\
\text { no }\end{array}$ & $\begin{array}{l}1,365 \\
6,394\end{array}$ & $\begin{array}{l}17.6 \\
82.4\end{array}$ \\
\hline Obese & $\begin{array}{l}\text { yes } \\
\text { no }\end{array}$ & $\begin{array}{l}651 \\
7,108\end{array}$ & $\begin{array}{l}8.4 \\
91.6\end{array}$ \\
\hline Dog & $\begin{array}{l}\text { yes } \\
\text { no } \\
\text { missing } \\
\text { single } \\
\text { multiple }\end{array}$ & $\begin{array}{l}1,391 \\
5,243 \\
1,125 \\
1,100 \\
291\end{array}$ & $\begin{array}{l}21.0 \\
79.0 \\
16.6 \\
4.4\end{array}$ \\
\hline Dog history & $\begin{array}{l}\text { never } \\
\text { sometimes } \\
\text { always } \\
\text { missing }\end{array}$ & $\begin{array}{l}3,810 \\
870 \\
790 \\
2,289\end{array}$ & $\begin{array}{l}69.7 \\
15.9 \\
14.4\end{array}$ \\
\hline Gender & $\begin{array}{l}\text { male } \\
\text { female } \\
\text { missing }\end{array}$ & $\begin{array}{l}3,946 \\
3,813 \\
0\end{array}$ & $\begin{array}{l}50.9 \\
49.1\end{array}$ \\
\hline Ethnicity & $\begin{array}{l}\text { white } \\
\text { other than white combined } \\
\text { missing }\end{array}$ & $\begin{array}{l}5,568 \\
197 \\
1,194\end{array}$ & $\begin{array}{l}96.6 \\
3.4\end{array}$ \\
\hline Number of people in household & $\begin{array}{l}3 \\
4 \\
5+ \\
\text { missing }\end{array}$ & $\begin{array}{l}935 \\
3,419 \\
2,316 \\
1,089\end{array}$ & $\begin{array}{l}14.0 \\
51.3 \\
34.7\end{array}$ \\
\hline Presence of an older sibling at 18 months & $\begin{array}{l}\text { yes } \\
\text { no } \\
\text { missing }\end{array}$ & $\begin{array}{l}3,883 \\
3,282 \\
597\end{array}$ & $\begin{array}{l}54.2 \\
45.8\end{array}$ \\
\hline Maternal education & $\begin{array}{l}\text { CSE or no qualification (lowest) } \\
\text { vocational } \\
\text { O level } \\
\text { A level } \\
\text { degree (highest) } \\
\text { missing }\end{array}$ & $\begin{array}{l}988 \\
648 \\
2,642 \\
1,983 \\
1,200 \\
298\end{array}$ & $\begin{array}{l}13.2 \\
8.8 \\
35.4 \\
26.6 \\
16.1\end{array}$ \\
\hline Paternal education & $\begin{array}{l}\text { CSE or no qualification (lowest) } \\
\text { vocational } \\
\text { O level } \\
\text { A level } \\
\text { degree (highest) } \\
\text { missing }\end{array}$ & $\begin{array}{l}1,435 \\
572 \\
1,627 \\
2,028 \\
1,594 \\
503\end{array}$ & $\begin{array}{l}19.8 \\
7.9 \\
22.4 \\
28.0 \\
22.0\end{array}$ \\
\hline
\end{tabular}


Table 1. Continued

\begin{tabular}{|c|c|c|c|}
\hline Variable ( ${ }^{*}=$ specific to 85 months) & Level & Number & Percentage \\
\hline Maternal social class & $\begin{array}{l}\text { professional (highest) } \\
\text { managerial and technical } \\
\text { skilled: non-manual } \\
\text { skilled: manual } \\
\text { partly skilled } \\
\text { unskilled (lowest) } \\
\text { missing }\end{array}$ & $\begin{array}{l}456 \\
2,215 \\
2,710 \\
432 \\
528 \\
92 \\
1,326\end{array}$ & $\begin{array}{l}7.1 \\
34.4 \\
42.1 \\
6.7 \\
8.2 \\
1.4\end{array}$ \\
\hline Paternal social class & $\begin{array}{l}\text { professional (highest), } \\
\text { managerial and technical } \\
\text { skilled: non-manual } \\
\text { skilled: manual } \\
\text { partly skilled } \\
\text { unskilled (lowest) } \\
\text { missing }\end{array}$ & $\begin{array}{l}862 \\
2,520 \\
797 \\
1,934 \\
573 \\
166 \\
907\end{array}$ & $\begin{array}{l}12.6 \\
36.8 \\
11.6 \\
28.2 \\
8.4 \\
2.4\end{array}$ \\
\hline Maternal age at delivery & $\begin{array}{l}<21 \text { years } \\
21-30 \text { years } \\
>30 \text { years } \\
\text { missing }\end{array}$ & $\begin{array}{l}252 \\
4,708 \\
2,799 \\
0\end{array}$ & $\begin{array}{l}3.3 \\
60.7 \\
36.1\end{array}$ \\
\hline Mother had pets as a child & $\begin{array}{l}\text { no, not at all } \\
\text { yes, part of time } \\
\text { yes, always } \\
\text { missing }\end{array}$ & $\begin{array}{l}661 \\
3,111 \\
2,959 \\
1,028\end{array}$ & $\begin{array}{l}9.8 \\
43.2 \\
44.0\end{array}$ \\
\hline House type & $\begin{array}{l}\text { detached } \\
\text { semi-detached } \\
\text { end terrace } \\
\text { terraced } \\
\text { flat/room in someone else's } \\
\text { house/other } \\
\text { missing }\end{array}$ & $\begin{array}{l}2,020 \\
2,496 \\
612 \\
1,300 \\
236 \\
1,095\end{array}$ & $\begin{array}{l}30.3 \\
37.5 \\
9.2 \\
19.5 \\
3.5\end{array}$ \\
\hline Parental obesity pre-pregnancy & $\begin{array}{l}\text { neither } \\
\text { either or both } \\
\text { missing }\end{array}$ & $\begin{array}{l}4,878 \\
646 \\
2,235\end{array}$ & $\begin{array}{l}88.3 \\
11.7\end{array}$ \\
\hline $\begin{array}{l}\text { Maternal number of cigarettes per day } \\
\text { during pregnancy }\end{array}$ & $\begin{array}{l}\text { none } \\
1-9 \\
10-19 \\
20+ \\
\text { missing }\end{array}$ & $\begin{array}{l}6,242 \\
457 \\
452 \\
150 \\
458\end{array}$ & $\begin{array}{l}85.5 \\
6.3 \\
6.2 \\
2.1\end{array}$ \\
\hline TV watching at 38 months (per week) & $\begin{array}{l}<4 \mathrm{~h} \\
4-8 \mathrm{~h} \\
>8 \mathrm{~h} \\
\text { missing }\end{array}$ & $\begin{array}{l}1,530 \\
3,222 \\
2,080 \\
927\end{array}$ & $\begin{array}{l}22.4 \\
47.2 \\
30.4\end{array}$ \\
\hline Sleep duration at 30 months & $\begin{array}{l}<4 \mathrm{~h} \\
4.1-8 \mathrm{~h} \\
>8 \mathrm{~h} \\
\text { missing }\end{array}$ & $\begin{array}{l}335 \\
3,678 \\
2,813 \\
933\end{array}$ & $\begin{array}{l}4.9 \\
53.9 \\
41.2\end{array}$ \\
\hline
\end{tabular}

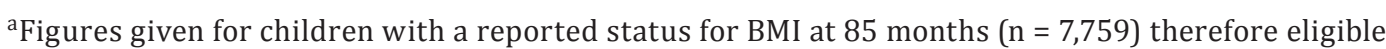
for multivariable modelling. 
Westgarth et al.: Is Childhood Obesity Influenced by Dog Ownership? No CrossSectional or Longitudinal Evidence

Table 2. Univariable analysis of overweight or obese, and obese, at 7 years $(n=7,759)$ with dog ownership at 7 years $(85$ months) or history of owning a dog

\begin{tabular}{|c|c|c|c|c|c|c|c|c|c|c|}
\hline \multirow[b]{2}{*}{ Variable } & \multicolumn{5}{|c|}{ Overweight or obese } & \multicolumn{5}{|l|}{ Obese } \\
\hline & $\begin{array}{l}\text { BMI SDS } \\
<1.04 \\
\text { n }(\%)\end{array}$ & $\begin{array}{l}\text { BMI SDS } \\
\geq 1.04 \\
\text { n (\%) }\end{array}$ & $\mathrm{OR}$ & $95 \% \mathrm{CI}$ & $P$ & $\begin{array}{l}\text { BMI SDS } \\
<1.64 \\
\text { n }(\%)\end{array}$ & $\begin{array}{l}\text { BMI SDS } \\
\geq 1.64 \\
\text { n (\%) }\end{array}$ & OR & $95 \% \mathrm{CI}$ & $\mathrm{P}$ \\
\hline \multicolumn{11}{|c|}{ Dog at 7 years } \\
\hline No & 4,365 (83.3) & $878(16.7)$ & 1 & & & $4,853(92.6)$ & $390(7.4)$ & & & \\
\hline Yes & $1,138(81.8)$ & $253(18.2)$ & 1.11 & $0.95-1.29$ & 0.20 & $1,257(90.4)$ & $134(9.6)$ & 1.33 & $1.08-1.63$ & 0.01 \\
\hline \multicolumn{11}{|c|}{ Number of dogs at 7 years } \\
\hline None & $4,365(83.3)$ & $878(16.8)$ & 1 & & & $4,853(92.6)$ & $390(7.4)$ & 1 & & \\
\hline Single & $894(81.3)$ & $206(18.7)$ & 1.15 & $0.97-1.36$ & 0.11 & $991(90.1)$ & $109(9.9)$ & 1.37 & $1.10-1.71$ & 0.01 \\
\hline Multiple & $244(83.9)$ & $47(16.2)$ & 0.96 & $0.70-1.32$ & 0.79 & $266(91.4)$ & $25(8.6)$ & 1.17 & $0.77-1.78$ & 0.47 \\
\hline \multicolumn{11}{|l|}{ Dog history } \\
\hline Sometimes & $689(79.2)$ & $181(20.8)$ & 1 & & & $769(88.4)$ & $101(11.6)$ & & & \\
\hline Never & $3,186(83.6)$ & $624(16.4)$ & 0.75 & $0.62-0.90$ & $<0.002$ & 3,535 (92.8) & $275(7.2)$ & 0.59 & $0.47-0.75$ & $<0.001$ \\
\hline Always & $650(82.3)$ & 140 (17.7) & 0.82 & $0.65-1.05$ & 0.11 & 725 (91.8) & $65(8.2)$ & 0.68 & $0.49-0.95$ & 0.02 \\
\hline
\end{tabular}

\section{Univariable Results}

Outcomes for overweight and obese, and obese, were compared with those who did and did not own a dog (table 2). Dog ownership at 7 years was associated with a higher likelihood of being obese (Odds ratio $(\mathrm{OR})=1.33,95 \%$ 95\% confidence interval $(\mathrm{CI})=1.08-1.63$, $\mathrm{p}=0.01$ ). If 'sometimes owning a dog' was set as the reference category, these children were more likely to be overweight or obese than those children who had never owned a dog $(\mathrm{OR}=0.75,95 \% \mathrm{CI}=0.62-0.90, \mathrm{p}<0.002)$, but not those who had always owned a dog $(\mathrm{OR}=0.82,95 \% \mathrm{CI}=0.65-1.05, \mathrm{p}=0.11)$. Findings were similar in respect to obesity: children who sometimes owned a dog were more likely to be obese than both those children who had never owned a $\operatorname{dog}(\mathrm{OR}=0.59,95 \% \mathrm{CI}=0.47-0.75, \mathrm{p}<0.001)$ and those who had always owned a dog (OR $=0.68,95 \% \mathrm{CI}=0.49-0.95, \mathrm{p}=0.02)$.

The number of dogs in the household was associated with obesity, but not with overweight or obesity (table 2). Of those who did not own a dog, 7.4\% were obese, compared to $9.9 \%$ and $8.6 \%$ of those with a single dog and or multiple dogs, respectively. Those with single dogs were more likely to be obese $(\mathrm{OR}=1.37,95 \% \mathrm{CI}=1.10-1.71, \mathrm{p}=0.01)$ than those without a dog; however, there was no evidence that those with multiple dogs were more or less likely to be obese than those without a $\operatorname{dog}(p=0.47)$. Data were also explored using the alternative nominal outcome 'neither overweight nor obese', 'overweight only', and 'obese only', but it made no difference to the findings (data not shown).

\section{Multivariable Results}

After adjusting for confounding factors associated with dog ownership, evidence remained for an association between overweight or obesity and dog ownership history, and obesity and current dog ownership or dog-owning history (table 3, model 1). However, after adjusting for confounding factors associated with risk of obesity (table 3, model 2), no associations remained, thereby confirming that these earlier apparent associations were due to confounding. Data were also explored using the nominal outcome 'neither overweight nor obese/overweight/obese', but it made no difference to the findings (data not shown). 
Table 3. Multivariable logistic regression model of dog ownership as a predictor of overweight or obese at 7 years, adjusted for confounding factors

\begin{tabular}{|c|c|c|c|c|c|c|}
\hline \multirow[t]{2}{*}{ Outcome variable } & \multicolumn{3}{|c|}{$\begin{array}{l}\text { Model } 1 \text { (adjusted for variables } \\
\text { indicated in Westgarth et al. [25] } \\
\text { model of dog ownership*) }\end{array}$} & \multicolumn{3}{|c|}{$\begin{array}{l}\text { Model } 2 \text { (adjusted for variables } \\
\text { indicated in Reilly et al. [5], with } \\
\text { addition of maternal social class }{ }^{\$} \text { ) }\end{array}$} \\
\hline & OR & $95 \% \mathrm{CI}$ & $\mathrm{p}$ value & OR & $95 \% \mathrm{CI}$ & $\mathrm{p}$ value \\
\hline \multicolumn{7}{|l|}{ Overweight or obese } \\
\hline \multicolumn{7}{|l|}{ Dog at 7 years } \\
\hline No & 1.00 & & & 1.00 & & \\
\hline Yes & 1.11 & $0.92-1.35$ & 0.28 & 1.07 & $0.86-1.34$ & 0.52 \\
\hline \multicolumn{7}{|c|}{ Number of dogs at 7 years } \\
\hline None & 1.00 & & & 1.00 & & \\
\hline Single & 1.09 & $0.89-1.35$ & 0.40 & 1.09 & $0.86-1.39$ & 0.46 \\
\hline Multiple & 1.18 & $0.81-1.74$ & 0.39 & 0.99 & $0.63-1.57$ & 0.98 \\
\hline \multicolumn{7}{|c|}{$\begin{array}{l}\text { Dog ownership history } \\
\text { (up to } 7 \text { years) }\end{array}$} \\
\hline Sometimes & 1.00 & & & 1.00 & & \\
\hline Never & 0.80 & $0.64-0.99$ & 0.04 & 0.89 & $0.69-1.16$ & 0.41 \\
\hline Always & 0.89 & $0.67-1.18$ & 0.43 & 1.01 & $0.72-1.41$ & 0.97 \\
\hline \multicolumn{7}{|l|}{ Obese } \\
\hline \multicolumn{7}{|l|}{ Dog at 7 years } \\
\hline No & & & & 1.00 & & \\
\hline Yes & 1.30 & $1.00-1.70$ & 0.05 & 1.18 & $0.88-1.59$ & 0.27 \\
\hline \multicolumn{7}{|c|}{ Number of dogs at 7 years } \\
\hline None & 1.00 & & & 1.00 & & \\
\hline Single & 1.25 & $0.94-1.67$ & 0.13 & 1.22 & $0.88-1.68$ & 0.23 \\
\hline Multiple & 1.52 & $0.92-2.50$ & 0.10 & 1.03 & $0.55-1.93$ & 0.92 \\
\hline \multicolumn{7}{|c|}{$\begin{array}{l}\text { Dog ownership history } \\
\text { (up to } 7 \text { years) }\end{array}$} \\
\hline Sometimes & 1.00 & & & 1.00 & & \\
\hline Never & 0.69 & $0.51-0.93$ & 0.01 & 0.80 & $0.56-1.14$ & 0.21 \\
\hline Always & 0.79 & $0.54-1.16$ & 0.23 & 0.82 & $0.52-1.31$ & 0.41 \\
\hline \multicolumn{7}{|c|}{$\begin{array}{l}{ }^{*} \mathrm{n}=4,979 \text {. Adjusted for concurrent ownership of bird, fish, 'other' pet, number of people in household, } \\
\text { presence of an older sibling, maternal social class, paternal social class, paternal education, maternal age } \\
\text { at delivery, house type, whether mother owned pets as a child. } \\
\$ \mathrm{n}=3,866 \text {. Adjusted for maternal education, maternal social class, maternal smoking during pregnancy, } \\
\text { parental obesity, gender of child, birth weight, TV watching at } 38 \text { months, sleep duration at } 30 \text { months. }\end{array}$} \\
\hline
\end{tabular}

\section{Change in BMI between 7 and 9 Years}

There was strong evidence of a higher BMI SDS at age 9 compared to 7 years (mean 0.28 compared to 0.10 , paired t-test $p<0.001$ ) within the 6,360 children with BMI measures on both occasions. There was no evidence of more or less BMI SDS change between those who owned a dog at age $8(1,173)$ and those who did not $(4,307)$ (mean change 0.17 for those who owned a dog and 0.18 for those who did not; t-test $\mathrm{p}=0.66)$.

\section{Stratification by Weight Status}

Due to the size of the ALSPAC dataset and the longitudinal data collection method, it was possible to stratify the samples in order to assess for effect of dog ownership on different groups. Ownership of a dog did not affect whether a child remained obese or overweight between ages 7-9 years (data not shown). 
Fig. 1. Effect of dog acquisition at age 7 years stratified into obese and not obese. a Of those children who were obese and did not own a dog at age 7 years ( $\mathrm{n}=293), 12$ children had acquired a dog by age 8 years; all 12 were still obese by age 9 years, whereas $13 \%$ of the rest of the group were now not obese (Fisher's exact $\mathrm{p}=$ 0.38). Mean BMI SDS increase between 7 and 9 years was 0.04 for those who did not get a dog at age 8 years and 0.10 for those who did get a dog (ttest $p=0.63$ ). There was also no evidence for differences regarding the larger subset $(n=669)$ of overweight children (data not shown). b A subset of children were not obese and did not own a dog at age 7 years $(n=3,821)$. Of the 132 children who now owned a dog at age 8 years, 7 (5\%) were obese by age 9 years, compared to $6 \%$ of the rest of the group ( $p=0.83)$. A smaller cohort of children were not overweight at age 7 years, and did not own a dog $(n=3,445)$. Of the 117 children who had acquired a dog by age 8 years, $14(12 \%)$ were now classed as overweight, compared to $11 \%$ of those remaining without a $\operatorname{dog}(\mathrm{p}=0.76)$.

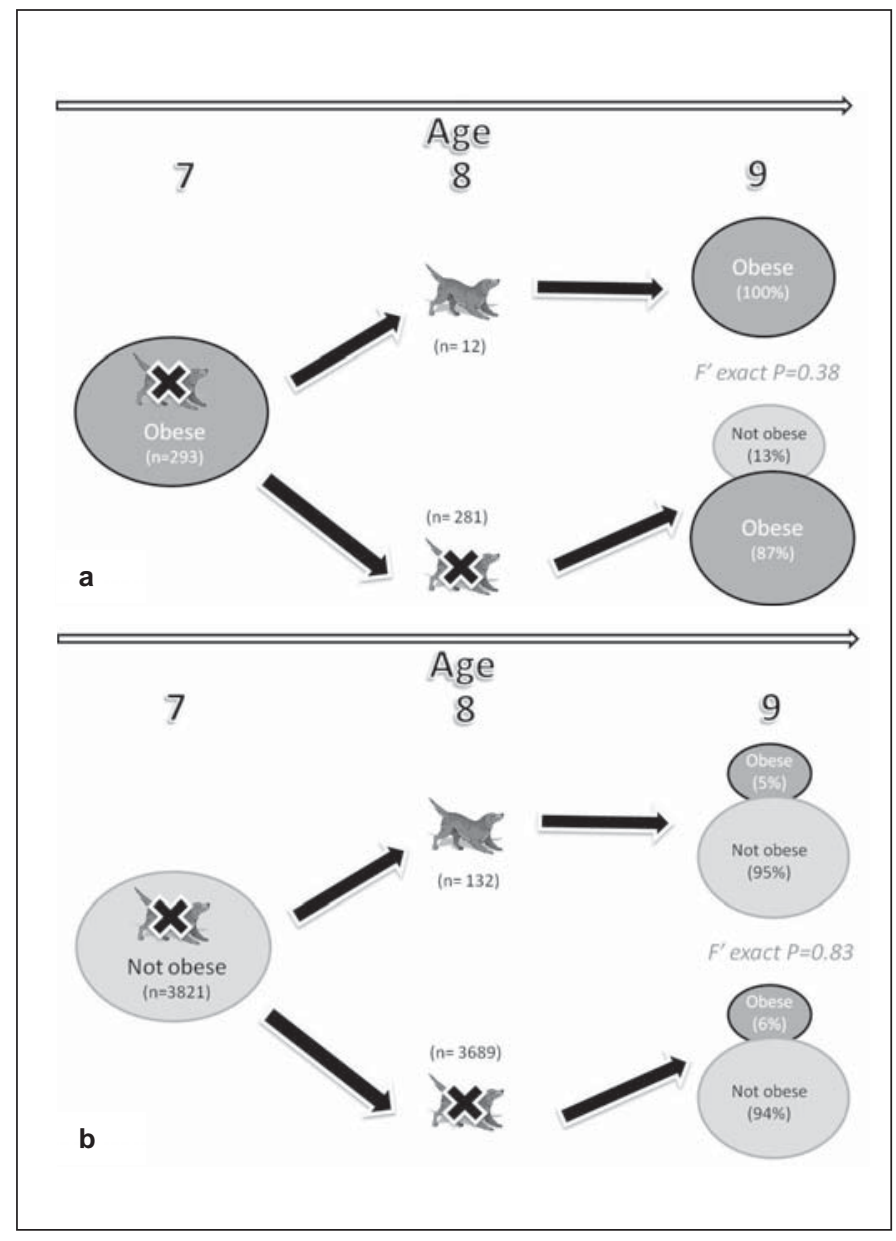

\section{The Effect of Dog Acquisition}

It was also possible to perform simple exploratory analyses by stratifying the samples in order to assess for any effect of dog acquisition (fig. 1); there was no evidence of an effect.

\section{Discussion}

This study provides no evidence that dog ownership is directly associated with childhood obesity at the population level. Apparent associations between weight status and dog ownership were attenuated after adjustment for socio-economic and demographic factors related to dog ownership [25], and disappeared once adjusted for other known predictors of childhood obesity [4]. There was no dose-response effect of time spent owning a dog, further suggesting that the apparent association was due to confounding. Acquisition of a dog after age 7 years did not have an effect on weight status at age 9 years; in fact, BMI increased within dog owners as well as non-dog owners.

The major challenges to Human-Animal Interaction (HAI) research are the methodological difficulties encountered in studying this complex relationship and assigning direction of causation [5, 29, 30]. Many studies have been cross-sectional in nature, with few longitudinal studies reported [5, 29]. Issues with confounding have also been a problem, 
particularly as demographic variables such as age, gender, socio-economics and ethnic status are known to be associated with many health behaviours [31, 32] and are also associated with pet ownership [25]. Thus this use of the ALSPAC dataset has considerable strengths and advantages over populations previously studied because it is well characterised and has a large sample size, longitudinal design and use of multivariable analysis. As a result, the dataset is powerful, allowing relatively small effect sizes to be identified. Further, the outcome measures were derived from clinic-measured weight and height, which are likely to be more reliable than self-reported measures. Other variables such as those relating to socio-economic status, and the variables regarding dog ownership, were based on self-report from the mother or main carer, which may be subject to reporting bias. However, it is unlikely that dog ownership was under- or over-reported, since it was collected at the time (thus would not suffer from recall bias), and it is difficult to reason why the owner would not accurately report this.

However, the study is limited in that the findings are representative of only one population of children in the UK, in the late 1990s / early 2000s, and it may not be appropriate to generalise to other populations and time periods. However, although ethnic minority groups are marginally under-represented at baseline, the ALSPAC cohort is known to be broadly representative of the UK population at the time [26]. An assumption was also made that the subject children also lived with the dogs reported by their mothers/main carers, and there may have been exceptions to this. We also only had limited infor mation about dog ownership, for example we had no indication of size, breed or weight status of the dog itself, which may provide further insight.

Our findings contrast with those of a study of primary school children in Australia, which suggested that young children (5-6 years) were less likely to be obese if they owned a dog [21]. This may be due to geographical and cultural differences between the UK and Australia, the larger sample size used in our study, age differences or adjustment for a larger number of confounding factors, including pre-pregnancy and early-life risk factors for obesity.

A recent UK study (Child Heart and Health Study in England - CHASE) suggested that physical activity in children aged 9-10 years may be higher if they own a dog [19]; it would be interesting to ascertain whether these dog-owning children also had lower weight status, and conversely whether, in ALSPAC, dog-owning children were more active (unfortunately an objective measure of activity is not available in the dataset at this age). Amalgamation of the findings from these two studies may suggest that the increased activity from owning a dog is insufficient to affect weight status. Such a hypothesis is plausible given that dog-owning children were only more active by an average 357 steps per day [19]. In fact, many interventions to improve physical activity in children do not reduce BMI [33]. In addition, a study of the pregnant ALSPAC mothers also did not identify any association between dog ownership and weight status, despite dog owners being more active through increased 'brisk walking' activity [34]. Obesity is a complex and multifactorial condition with a multitude of predisposing factors including food intake, physical activity and lifestyle factors such as family behaviours; such factors may also need to be evaluated in such studies.

This study demonstrates the importance of controlling for various behavioural and environmental factors, and particularly socio-economic status, that are known to affect both dog ownership and health outcomes. In this population, a higher proportion of children that owned dogs were obese than those that did not own dogs. However, the association is not likely to be causal and, instead, the result of children from dog-owning families being obese due to other factors such as socio-economic status. These families also tended towards 'sometimes' having a dog rather than 'always' or 'never'. One possible interpre- 
tation is that families with obese children might acquire a dog to increase their activity levels or to provide emotional support. However, given the effect of adjustment for confounding variables, it is more likely that these families are more likely to 'sometimes' own dogs for other reasons, rather than there being a direct link between the acquisition of dogs and weight status.

Future research should investigate, in detail, the involvement of children in different activities associated with dog ownership, such as caring, walking and playing, and how this contributes to their general activity levels. Population studies should examine the threeway relationship between dog ownership, activity levels and weight status, to inform whether dog ownership can influence activity levels but not sufficiently to impact weight status (as there is some suggestion that this may be the case in adults [34]), or whether the relationship between dog ownership and activity levels differs in obese and non-obese children. This would ideally use the most objective measures available and include direct observations and information on frequency of dog walking. It would also be useful to examine whether there is a positive association between the weight status of children and the weight status of their dogs, or differences related to size or type of dog, and the intensity of relationship that the child has with the dog.

In summary, in this population there is no evidence for a protective effect of dog ownership per se against childhood obesity as measured by BMI. This study confirms that obese and overweight children do own dogs, but more investigation is required to determine how living with a dog impacts their physical activity and how interventions to increase physical activity, and ultimately weight status, through dog walking might be designed.

\section{Acknowledgements}

We are extremely grateful to all the families who took part in this study, the midwives for their help in recruiting them, and the whole ALSPAC team, which includes interviewers, computer and laboratory technicians, clerical workers, research scientists, volunteers, managers, receptionists and nurses. ALSPAC is supported by the Medical Research Council, Wellcome Trust, UK Department of Health, Department of the Environment, Department of Education and the Environment, National Institutes of Health, and a variety of medical research charities and commercial companies. ALSPAC is run as a supported access resource. Full details of the collaboration policy can be found at www.bristol.ac.uk/alspac/ sci-com/collab-policy/.

\section{Disclosure Statement}

We declare that i) CW, SD, RG, PB, AG, and KC have institutional support via a grant from WALTHAM ${ }^{\circledR}$ and Mars Petcare UK for the submitted work; CW's position was funded through this work; ii) the position of AG at the institution is funded by Royal Canin, a subsidiary of Mars Petcare UK and he has also received other research grants from Mars Petcare UK iii) SMcC is an employee (Research Manager) of WALTHAM ${ }^{\circledR}$, a division of Mars Inc; iv) AN and JH received no institutional or personal funding for this work; v) no spouses, partners, or children have financial relationships that may be relevant to the submitted work; and vi) no authors have non-financial interests that may be relevant to the submitted work. The funding sources had input during study design, interpretation of results and writing of the manuscript but did not influence study findings.. All researchers except SM are independent of the main funding body. 
Westgarth et al.: Is Childhood Obesity Influenced by Dog Ownership? No Cross-

Sectional or Longitudinal Evidence

\section{References}

- 1 Buchan IE, Bundred PE, Kitchiner DJ, Cole TJ: Body mass index has risen more steeply in tall than in short 3-year olds: serial cross-sectional surveys 1988-2003. Int J Obes (Lond) 2007;31:23-29.

- 2 Bundred P, Kitchiner D, Buchan I: Prevalence of overweight and obese children between 1989 and 1998:Population based series of cross sectional studies. BMJ 2001;322:326-328.

- 3 Prentice A, Jebb S: Obesity in Britain: gluttony or sloth? BMJ 1995;311:437-439.

$\checkmark 4$ Reilly JJ, Armstrong J, Dorosty AR, Emmett PM, Ness A, Rogers I, Steer C, Sherriff A: Early life risk factors for obesity in childhood: cohort study. BMJ 2005;330:1357-1359.

- 5 Headey B: Pet ownership: good for health? Med J Aust 2003;179:460-461.

- 6 McNicholas J, Gilbey A, Rennie A, Ahmedzai S, Dono J-A, Ormerod E: Pet ownership and human health: a brief review of evidence and issues. BMJ 2005;331:1252-1254.

7 O'Haire M: Companion animals and human health: benefits, challenges, and the road ahead. J Vet Behav 2010;5:226-234.

- 8 Herzog H: The impact of pets on human health and psychological well-being: facto, fiction, or hypothesis? Curr Dir Psychol Sci 2011;20:236-239.

- 9 Cutt H, Giles-Corti B, Knuiman M, Burke V: Dog ownership, health and physical activity: a critical review of the literature. Health Place 2007;13:261-272.

10 Bauman AE, Russell SJ, Furber SE, Dobson AJ: The epidemiology of dog walking: an unmet need for human and canine health. Med J Aust 2001;175:632-634.

11 Serpell J: Beneficial effects of pet ownership on some aspects of human health and behavior. J R Soc Med 1991;84:717-720.

12 Thorpe RJ, Simonsick EM, Brach JS, Ayonayon H, Satterfield S, Harris TB, Garcia M, Kritchevsky SB, Health, Aging and Body Composition Study: Dog ownership, walking behavior, and maintained mobility in late life. J Am Geriatr Soc 2006;54:1419-1424.

13 Cutt H, Giles-Corti B, Knuiman M, Timperio A, Bull F: Understanding dog owners' increased levels of physical activity: results from reside. Am J Public Health 2008;98:66-69.

14 Brown SG, Rhodes RE: Relationships among dog ownership and leisure-time walking in western Canadian adults. Am J Prev Med 2006;30:131-136.

15 Harris TJ, Owen CG, Victor CR, Adams R, Cook DG: What factors are associated with physical activity in older people, assessed objectively by accelerometry? Br J Sports Med 2009;43:442-450.

16 Coleman KJ, Rosenberg DE, Conway TL, Sallis JF, Saelens BE, Frank LD, Cain K: Physical activity, weight status, and neighborhood characteristics of dog walkers. Prev Med 2008;47:309-312.

17 Thorpe RJ, Kreisle RA, Glickman LT, Simonsick EM, Newman AB, Kritchevsky S: Physical activity and pet ownership in year 3 of the Health ABC study. J Aging Phys Act 2006;14:154-168.

18 Holmes KL, Morris PJ, Abdulla Z, Hackett RM, Rawlings JM: Risk factors associated with excess body weight in dogs in the UK. J Anim Physiol Anim Nutr 2006;91:166-167.

19 Owen CG, Nightingale CM, Rudnicka AR, Ekelund U, McMinn AM, Van Sluijs EMF, Griffin SJ, Cook DG, Whincup PH: Family dog ownership and levels of physical activity in childhood: findings from the Child Heart and Health Study in England. Am J Public Health 2010;100:1669-1671.

20 Salmon J, Timperio A, Chu B, Veitch J: Dog ownership, dog walking, and children's and parents' physical activity. Res Q Exerc Sport 2010;81:264-271.

21 Timperio A, Salmon J, Chu B, Andrianopoulos N: Is dog ownership or dog walking associated with weight status in children and their parents? Health Promot J Aust 2008;19:60-63.

22 Mathers M, Canterford L, Olds T, Waters E, Wake M: Pet ownership and adolescent health: cross-sectional population study. J Paediatr Child Health 2010;46:729-735.

23 Yam P, Morrison R, Penpraze V, Westgarth C, Ward D, Mutrie N, Hutchison P, Young D, Reilly J: Children, Parents, and Pets Exercising Together (CPET) randomised controlled trial: study rationale, design, and methods. BMC Public Health 2012;12:208.

24 Murray JK, Browne WJ, Roberts MA, Whitmarsh A, Gruffydd-Jones TJ: Number and ownership profiles of cats and dogs in the UK. Vet Rec 2010;166:163-168.

25 Westgarth C, Heron J, Ness AR, Bundred P, Gaskell RM, Coyne KP, German AJ, McCune S, Dawson S: Pet ownership during childhood: findings from a UK birth cohort and implications for public health research. Int J Environ Res Public Health 2010;7:3704-3729.

26 Golding J, Pembrey M, Jones R, Team AS: ALSPAC - the Avon Longitudinal Study of Parents and Children. I. Study methodology. Paediatr Perinat Epidemiol 2001;15:74-87.

27 Ness AR: The Avon Longitudinal Study of Parents and Children (ALSPAC) - a resource for the study of the environmental determinants of childhood obesity. Eur J Endocrinol 2004;151:U141-U149.

28 Cole TJ, Freeman JV, Preece MA: Body-mass index reference curves for the UK, 1990. Arch Dis Child 1995; $73: 25-29$

29 Wilson CC, Barker SB: Challenges in designing human-animal interaction research. Am Behav Sci 2003;47: $16-28$. 
30 Griffin JA, McCune S, Maholmes V, Hurley K: Human-animal interaction research: an introduction to issues and topics; in McCardle P, McCune S, Griffin JA, Maholmes V (eds): How Animals Affect Us: Examining the Influence of Human-Animal Interaction on Child Development and Human Health. Washington DC, American Psychological Association Press, 2010, pp 3-9.

31 Conner M, Norman P: Predicting health behaviour: a social cognition approach; in Conner M (ed): Predicting Health Behaviour. Berkshire, McGraw-Hill Education, 2005, pp 1-21.

32 Marmot M, Bell R: Fair society, healthy lives. Public Health 2012 ;126(suppl 1):S4-10.

-33 Harris KC, Kuramoto LK, Schulzer M, Retallack JE: Effect of school-based physical activity interventions on body mass index in children: a meta-analysis. Can Med Assoc J 2009;180:719-726.

34 Westgarth C, Liu J, Heron J, Ness AR, Bundred P, Gaskell RM, German AJ, McCune S, Dawson S: Dog ownership during pregnancy, maternal activity, and obesity: a cross-sectional study. PloS One 2012; 7:e31315. 